\title{
Arsitektur Internet of Things (IoT) Berskala Industri Dengan Fitur Auto Provisioning
}

\author{
I Putu Oka Wisnawa ${ }^{1}$, I Putu Widia Prasetia ${ }^{2}$, Cardian Althea Stephanie Lahallo ${ }^{3}$ \\ ${ }^{1,2,3}$ Program Studi Teknologi Informasi, Universitas Pendidikan Nasional
}

\begin{abstract}
Provisioning of IoT devices is one of the first steps that must be taken in the development of Internet of Things (IoT) networks. The term Provisioning for IoT devices means developing IoT devices to a state where they can be handed over to end users for their respective functionally specific uses. Provisioning of IoT devices is done when registering a new device or sensor to the system, then configuring it to send data to the system and authenticate to the cloud network or the company's on-premises network. In the provisioning process, authentication is required, because the authentication process is used to ensure that only secure and registered devices on the system are added to the corporate network. Authentication includes the process of verifying devices with the correct certifications and credentials. Devices can communicate with the IoT platform or local server with a secure connection such as using an SSL/TLS certificate or with a token that requires a name and password. Devices can upload data containing warnings or results obtained in many ways. Either from a device that directly adds data to the platform, or the device first sends data to a new local server and then sends it to the cloud-based IoT Platform. ThingsBoard is an open-source IoT platform with a website interface that allows users to develop, manage, collect data, visualize, and manage devices. ThingsBoard communicates with devices using commonly used protocols such as MQTT, CoAP, and HTTP. ThingsBoard allows users to design and configure IoT dashboards that can be tailored to the needs and desires of users. The Auto Provisioning feature is one of the features offered by the ThingsBoard Platform that allows provisioning of devices in a timely manner without requiring human intervention. The Auto Provisioning feature enables Provisioning of millions of IoT devices to the server in a secure and scalable manner. There are many Provisioning scenarios where the Auto Provisioning feature is a good choice for getting devices connected and configured to the server. In terms of security, the ThingsBoard platform is equipped with an access token-based security system, MQTT basic credentials, and X.509 certificate-based authentication.
\end{abstract}

Keywords: Provisioning, Internet of Things. ThingsBoard, MQTT, Auto Provisioning, Authentication.

\section{ABSTRAK}

Provisioning perangkat IoT adalah salah satu langkah pertama yang harus dilakukan dalam pengembangan dalam jaringan Internet of Things (IoT). Istilah Provisioning untuk perangkat IoT berarti mengembangkan perangkat IoT ke kondisi dimana perangkat tersebut dapat diserahkan ke pengguna akhir untuk penggunaan khusus secara fungsionalnya masingmasing. Provisioning perangkat IoT dilakukan ketika mendaftarkan perangkat atau sensor baru ke sistem, kemudian melakukan konfigurasi untuk mengirim data ke sistem dan melakukan autentikasi ke jaringan cloud atau jaringan lokal perusahaan. Dalam proses Provisioning diperlukan adanya otentikasi, karena proses otentikasi digunakan untuk memastikan hanya perangkat yang aman dan terdaftar pada sistem yang ditambahkan ke jaringan perusahaan. Otentikasi mencakup proses verifikasi perangkat dengan sertifikasi dan kredensial yang benar. Perangkat dapat berkomunikasi dengan platform IoT atau server lokal dengan koneksi aman seperti menggunakan sertifikat SSL/TLS atau dengan token yang memerlukan nama dan kata sandi. Perangkat dapat mengunggah data yang berisikan peringatan atau hasil yang didapatkan dalam banyak cara. Baik dari perangkat yang secara langsung menambahkan data ke platform, atau perangkat mengirimkan data terlebih dahulu ke server lokal baru kemudian mengirimnya ke Platform IoT yang berbasis cloud. ThingsBoard merupakan salah satu platform IoT open-source dengan antarmuka website yang memungkinkan pengguna untuk melakukan pengembangan, pengelolaan, pengumpulan data, visualisasi, dan manajemen perangkat. ThingsBoard berkomunikasi dengan perangkat dengan protokol-protokol umum yang biasa digunakan seperti MQTT, CoAP, dan HTTP. ThingsBoard memungkinkan pengguna untuk melakukan perancangan dan konfigurasi dashboard IoT yang dapat disesuaikan dengan kebutuhan dan keinginan pengguna. Fitur Auto Provisioning adalah salah satu fitur yang ditawarkan oleh Platform ThingsBoard yang memungkinkan melakukan Provisioning perangkat secara tepat waktu tanpa memerlukan intervensi dari manusia. Fitur Auto Provisioning memungkinkan Provisioning jutaan perangkat IoT ke server dengan cara yang aman dan terukur. Ada banyak skenario Provisioning di mana fitur Auto Provisioning adalah pilihan yang tepat untuk membuat perangkat terhubung dan terkonfigurasi ke server. Dari segi keamanan platform ThingsBoard ini dilengkapi sistem keamanan berbasis token akses, MQTT basic credentials, dan Otentikasi berbasis sertifikat X.509.

Kata kunci: Provisioning, Internet of Things. ThingsBoard, MQTT, Auto Provisioning, Otentikasi. 


\section{Info Artikel}

$\begin{array}{llll}\text { Diterima Redaksi } & : & 01-11-2021 & \text { This is an open access article under the CC BY-SA license. } \\ \text { Selesai Revisi } & : & 01-12-2021 \\ \text { Diterbitkan Online } & : & 30-12-2021\end{array}$

Penulis Korespondensi:

I Putu Oka Wisnawa

Teknologi Informasi,

Universitas Pendidikan Na sional,

Jalan L.G Gambir No.49 Medahan, Kec. Blahbatuh, Gianyar 80581

widiaprasetia27@gmail.com

\section{PENDAHULUAN}

Provisioning perangkat IoT adalah salah satu langkah pertama yang harus dilakukan dalam pengembangan dalam jaringan IoT[1]. Istilah Provisioning untuk perangkat IoT berarti mengembangkan perangkat IoT ke kondisi dimana perangkat tersebut dapat diserahkan ke pengguna akhir untuk penggunaan khusus secara fungsionalnya masing-masing. Sebagai contoh anggap saja saat pertama kali membeli HP. Hal perta ma yang dilakukan adalah membuka dan mengeluarkannya darikotaknya dan menyalakannya. Kemudian melakukan konfigurasi seperti memilih bahasa, menyambungkan ke jaringan WiFi, dan serangkaian langkah lainnya. Perangkat IoT bekerja dengan cara yang serupa, perangkat IoT tersa mbung ke jaringan internet untuk memastikan bahwa perangkat bekerja dengan a man dan sesuaikeinginan.

Provisioning perangkat IoT dilakukan ketika mendaftarkan perangkat atau sensor baru ke sistem, kemudian melakukan konfigura si untuk mengirim data ke sistem dan melakukan autentika si ke jaringan cloud a tau jaringan lokal perusahaan. Menginstal sertifikat dan token pada perangkat IoT juga terma suk bagian dari Provisioning, menyajikkan data yang diha silkan oleh perangkat IoT untuk diunggah ke sistem/cloud agar bisa dilihat oleh user[2]. Otentikasi merupakan bagian dari proses Provisioning, karena proses otentikasi memastikan hanya perangkat yang aman dan terdaftar pada sistem yang ditambahkan ke jaringan perusahaan[3]. Otentikasi mencakup proses verifika si perangkat dengan sertifikasi dan kredensial yang benar. Kredensial seperti sertifikat dan key, mengetahui alamat server, dan dapat terhubung ke sistem dan mendaftarkan perangkat secara otomatis sendirinya.

Setiap perangkat perlu ditambahkan sistem informasi yang telah dibuat atau menggunakan Platform IoT apapun yang tersedia. Kemudian, ditautkan dengan peralatan atau objek yang akan dimonitoring. Perangkat berkomunikasi dengan platform IoT atau server lokal dengan koneksi a man seperti menggunakan sertifikat SSL/TLS atau dengan token yang memerlukan nama dan kata sandi. Perangkat dapat mengunggah data yang berisikan peringatan atau hasil yang didapatkan dalam banyak cara. Baik dari perangkat yang secara langsung menambahkan data ke platform, atau perangkat mengirimkan data terlebih dahulu ke server lokal baru kemudian mengirimnya ke Platform IoT yang berbasis cloud.

ThingsBoard merupakan salah satu Platform IoT open-source yang memungkinkan pengguna untuk melakukan pengembangan, pengelolaan, pengumpulan data, visualisasi, dan manajemen perangkat[4][5]. Untuk mendaftarkan perangkat yang akan digunakan di ThingsBoard, perangkat tersebut harus membuat akun atau profile terlebih dahulu. Setelah ditambahkan, token akses akan dibuat. Token akses ini diperlukan agar ThingsBoard mengumpulkan data telemetri dari perangkat dengan protokol-protokol umum yang biasa digunakan seperti MQTT, CoAP, dan HTTP[6]. ThingsBoard memungkinkan pengguna untuk melakukan perancangan dan konfigurasi dashboard IoT yang dapat disesuaikan dengan kebutuhan dan keinginan pengguna. Da shboard perangkat di ThingsBoard bia sanya berisi widget yang memvisualisa sikan data telemetri dari perangkat IoT yang berbeda. Widget tersebut berisi tabel, a larm, da n meteran dala m bentuk digital. Widget dashboard juga dapat dimodifikasi dengan bentuk yang sesuai dengan kein ginan pengguna [7].

Fitur Auto Provisioning adalah layanan pembantu yang disediakan oleh Platform ThingsBoard yang memungkinkan melakukan Provisioning secara tepat waktu tanpa memerlukan intervensi dari manusia. Fitur Auto Provisioning memungkinkan Provisioning jutaan perangkat IoT ke server dengan cara yang aman dan 
terukur[8]. Ada banyak skenario Provisioning dimana fitur Auto Provisioning adalah pilihan yang tepat untuk membuat perangkat terhubung dan terkonfigura si ke server.

\section{METODE PENELITIAN}

Penerapan fitur Auto Provisioning menggunakan platform ThingsBoard yang berbasis antarmuka website. Bagaimana alur kerja dari Auto Provisioning di ThingsBoard, konfigurasi dari sisi perangkat dan server.

\subsection{Alur Kerja Auto Provisioning pada ThingsBoard}

Setiap perangkat Internet of Things (IoT) dapat mengirim permintaan Provisioning request ke server ThingsBoard. Permintaan tersebut harus selalu berisi provision key dan secret key[9]. Permintaan secara opsional dapat menyertakan nama perangkat dan kredensial yang dihasilkan oleh perangkat IoT itu sendiri. Jika kredensial itu tidak a da, maka server akan merespon dengan menghasilkan Token Akses untuk digunakan oleh perangkat IoT yang mengirim permintaan Provisioning request ke ThingsBoard. ThingsBoard akan memvalidasi permintaan dan merespon dengan respon penyediaan perangkat (Device Provisioning). Respons yang berhasil tersebut berisikan id perangkat, jenis kredensial, dan isi. Jika validasi perangkat tidak berhasil, maka respon dari ThingsBoard hanya berupa pesan atau status error dan sebagainya. Selama va lidasi request, pertama ThingsBoard akan memeriksa Provision Device Key dan Provision Device Secret yang disediakan untuk menemukan profil perangkat yang sesuai dengan Device Profile yang sudah dibuat di ThingsBoard sebelumnya. Setelah profil ditemukan, ThingsBoard akan menggunakan Provision Strategy yang dikonfigura si untuk memvalidasi nama perangkat.

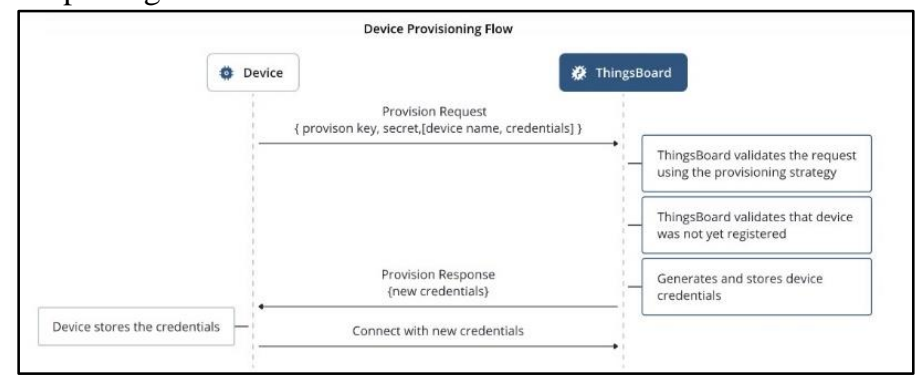

Gambar 1. Alur Device Provisioning pada ThingsBoard

Ada dua strategi Provisioning dalam ThingsBoard. Pertama adalah Allowing creating new devices atau mengizinkan perangkat untuk membuat perangkat baru. ThingsBoard memeriksa apakah perangkat dengan nama yang sama belum terdaftar di ThingsBoard. Strategi ini berguna ketika kita tidak mengetahui daftar nama unik perangkat seperti mac address dan lainnya selama pembuatan. Tetapi perangkat itu sendiri memiliki akses ke info ini di firmware. Lebih mudah untuk diterapkan, tetapi strategi ini kurang aman untuk diterapkan. Kemudian untuk strategi kedua adalah Checking pre-provisioned devices atau memeriksa perangkat yang telah disediakan sebelumnya. Strategi ini lebih aman diterapkan daripada strategi sebelumnya. ThingsBoard akan memeriksa perangkat dengan nama yang sama yang telah dibuat sebelumnya di ThingsBoard, tetapi perangkat belum di Provisioning[10]. Startegi ini berguna saat kita hanya ingin mengijinkan Provisioning hanya untuk daftar perangkat tertentu. Sebagai contohnya kita telah mengumpulkan daftarmac address dari perangkat selama pembuatan. Kita dapatmemanfaatkan fitur Bulk Provisioning untuk mengunggah daftar mac address perangkat tersebut ke ThingsBoard. Setelah itu perangkat tersebut dapat mengeluarkan request Provisioning ke ThingsBoard dan tidak ada perangkat lain yang dapat melakukan Provisioning sendiri karena sudah ada perangkat yang terhubung sebelumnya.

\subsection{Konfigurasi dari sisi server ThingsBoard}

Hal perta ma yang wajib dilakukan adalah melakukan konfigurasi pada ThingsBoard, yaitu pada menu Device Profiles. Konfigurasi pertama pada Device Profiles untuk mengaktifkan fitur Provisioning, agar mendapatkan provision device key dan provision device secret. Seperti yang ditunjukkan pada Gambar 1, membuat Device Profiles baru dengan cara membuka halaman menu Device Profiles dan mengklik ikon panah 
di pojok kanan atas. Kemudian mengisikan tabelDevice Profiles baru seperti nama dan deskripsi profil, setelah itu pilih salah satu Provision Strategy pada menu Device Provisioning.

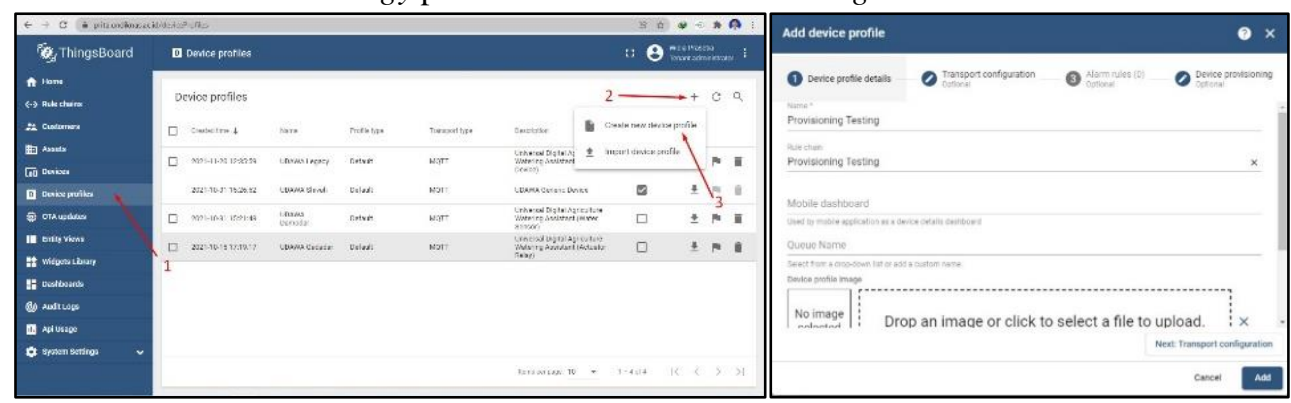

Gambar 2. Konfigurasi Device Profiles pada ThingsBoard

Pada kasus kali ini menggunakan protokolMQTT sebagai protokol komunikasi antara perangkat dan ThingsBoard yang dipilih pada menu Transport configuration. Untuk Provision Strategy menggunakan Check for pre-provisioned devices dengan alasan agar lebih aman seperti penjelasan dua Provision Strategy pada penjelasan diatas sebelumnya. Setelah itu akan muncul Provision Device Key dan Provision Device Secret yang akan disa lin untuk diguna kan oleh perangkat yang akan terhubung ke ThingsBoard.

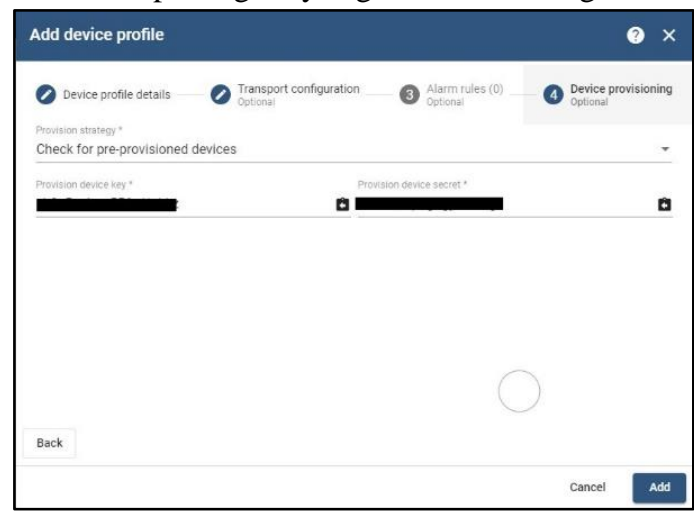

Gambar 3. Provision Strategy, Provision Device Key, dan Provision Device Secret

Langkah selanjutnya setelah membuat Device Profiles baru adalah menambah perangkat untuk terhubung ke ThingsBoard agar bisa menampilkan, mengolah, dan manajemen perangkat melalui dashboard Devices. Pilih pada menu Devices, klik ikon tambah pada pojok kanan atas dan pilih add new devices. Kemudian isikan nama perangkat dan deskripsi perangkat sesuai keingin an la lu terakhirklik add yang adapada bagian pojok kanan bawah.

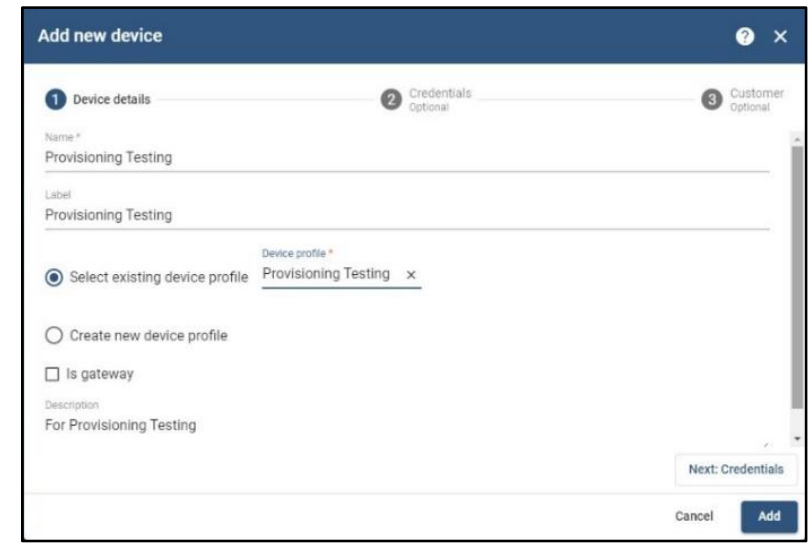

Gambar 4. Konfigurasi Penambahan Devices pada ThingsBoard

2.3. Konfigurasi pada Perangkat

Konfigurasi perangkat dilakukan dengan menyalin device provision key dan secret key yang didapatkan dari ThingsBoard setelah membuat Device Profiles. Konfigurasi dilakukan dengan menggunakan IDE Visual Studio Code dengan menggunakan ekstensi tambahan PlatformIO. PlatformIO sendiri adalah 
sebuah tools professional untuk pengembangan microcontroller atau embedded system. PlatformIO berisi kurang lebih 200 library yang digunakan untuk pengembangan perangkat embedded system [11]. Seperti yang ditunjukkan pada gambar 4 adalah konfigurasi perangkat agar terhubung ke server ThingsBoard dengan menambahkan parameter provisionDeviceKey dan provisionDeviceSecret yang didapatkan dari ThingsBoard.

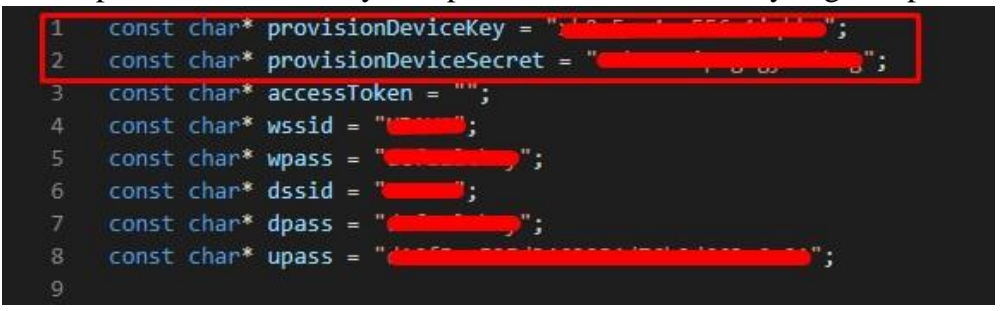

Gambar 5. Konfigurasi pada sisi perangkat

Setelah selesai melakukan konfigurasi perangkat melalui PlatformIO, kode program di build terlebih dahulu untuk memastikan apakah masih a da pesan erorr. Setelah berhasil di build, kode program di upload ke perangkat yangakan dihubungkan ke ThingsBoard.

\section{HASIL DAN PEMBAHASAN}

Hasil dari penerapan fitur Auto Provisioning menggunakan platform ThingsBoard adalah dari sisi perangkat yang dapat dilihat mela lui serial monitor IDE Visual Studio Code untuk mema stikan apakah benar perangkat sudah terhubung ke ThingsBoard. Sedangkan dari sisi server dapat dilihat dari website antamuka ThingsBoard.

\subsection{Hasil Provisioning dari Sisi Perangkat dan Server.}

Setelah melakukan upload kode program pada perangkat, untuk melihat perangkat sudah terhubung atau belum ke server ThingsBoard yang berala mat di prita.undiknas.ac.id:8883 dapat menggunakan tool serial monitor yang ada pada IDE Visual Studio Code. Pada Gambar 6 menunjukkan proses dari Provisioning, yang diawali dengan pesan "Starting provision to prita.undiknas.ac.id:8883". Pada serial monitor terdapat respon "processProvisionRespone: Provision response credential type: ACCES_TOKEN" yang artinya bahwa perangkat sudah berhasil Provisioning atau terhubung ke server prita.undiknas.ac.id:8883 dan akan mendapatkan kode token secara otomatis yang dapat dilihat di server ThingsBoard.

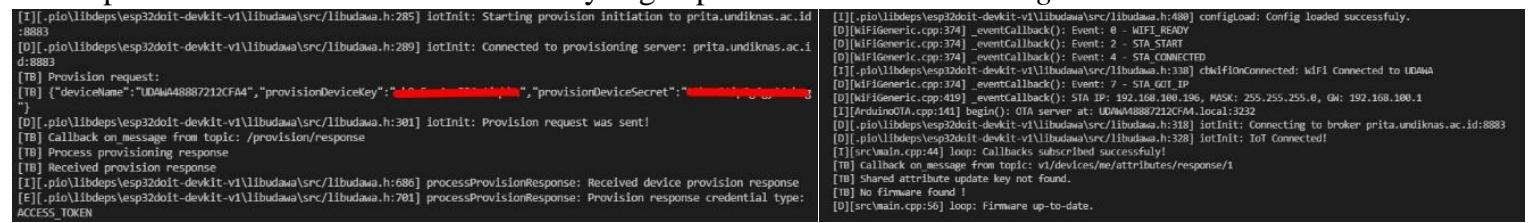

Gambar 6. Proses Provisioning di Serial Monitor IDE Visual Studio Code

Setelah memastikan perangkat sudah berhasil melakukan Provisioning, untuk memastikan pada sis server dapat dilihat pada menu Devices. Pada menu Devices pilih nama perangkat yang sudah dibuat dikonfigurasi sebelumnya pada server, kemudian pada tab "Attributes" ada field dengan nama "provisionState". Gambar 7 menunjukkan field dari provisionState adalah "provisioned", artinya pada sisi server perangkat sudah berhasil melakukan Provisioning dan terhubung ke server secara otomatis. 


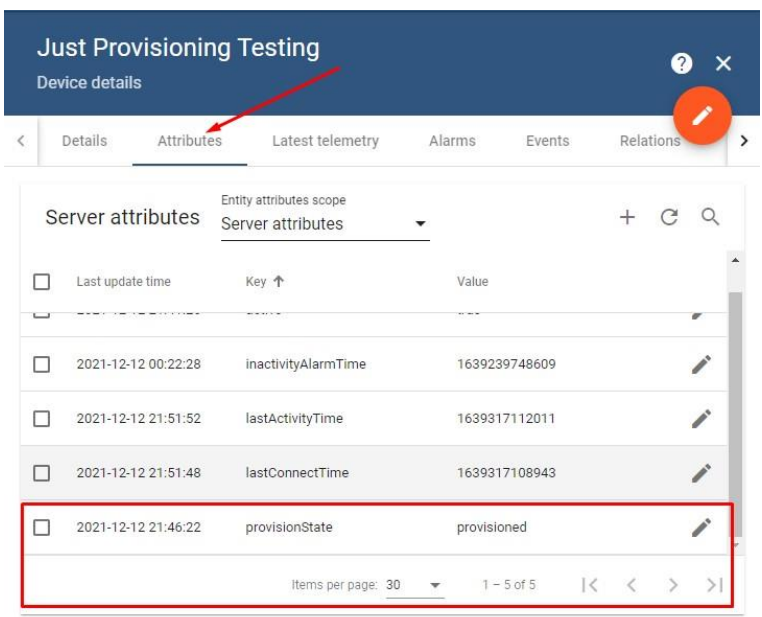

Gambar 7. Proses Provisioning Perangkat di ThingsBoard berhasil

Selama proses Auto Provisioning berlangsung perangkat dapat menghasilkan kredensial unik atau meminta ke server untuk memberikan kredensial yang unik untuk perangkat. Perangkat akan terhubung ke server melalui fitur Auto Provisioning. Dilihat dari sisi keamanan, setiap request Provisioning harus selalu berisi key dan secret yang khusus. Jika kredensial tersebut tidak ada, maka server akan menghasilkan token akses yang digunakan akan digunakan oleh perangkat. Auto Provisioning ThingsBoard juga dapat memeriksa perangkat dengan nama yang sa ma yang telah dibuat di ThingsBoard, tetapi belum melakukan Provisioning sama sekali. Halitu tentu sangat berguna ketika user hanya mengizinkan Provisioning untuk perangkat tertentu saja.

Walaupun ThingsBoard merupakan platform IoT yang berbasis Open-Source, tetapi ThingsBoard juga memiliki fitur keamanan yang berstandar industri. Fitur keamanan ThingsBoard mencakup algoritma enkripsi standar industri seperti SSL dan jenis kredensial untuk pendaftaran perangkat seperti sertifikat X.509 dan Token Akses[6]. Dukungan ThingsBoard untuk jenis kredensial keamanan perangkat dan penggunaan protokol MQTT menjadi alasan utama mengapa memilih menggunakan ThingsBoard. Karena tujuan utama menggunakan platform ini adalah untuk memastikan keamanan dan skalabilitas meskipun ada peningkatan jumlah perangkat pada jaringan IoT yang dibuat.

\section{KESIMPULAN}

Penulis mencoba untuk mengimplementasikan salah satu cara untuk menghubungkan perangkat dan server dengan menggunakan fitur Auto Provisioning dari platform IoT ThingsBoard. Perangkat harus dikonfigurasi terlebih dahulu menggunakan file yang berisi kode program yang kemudian di upload ke perangkat agar bisa terhubung ke server IoT ThingsBoard. Server ThingsBoard yang digunakan penulis berbasis Community Edition yang artinya Open-Source gratis dikembangkan oleh komunitas mana pun yang ingin berkolaborasike dalam projek. Server bisa diinstal sendiri di jaringan lokal atau bisa menggunakan fitur sewa cloud service tanpa perlu memikirkan infrastruktur lainnya, artinya server langsung siap pakai tanpa memikirkan hal teknis lainnya. Dalam proses menghubungkan/Provisioning perangkat ke server, perangkat harus menda patkan device dan secret key yang telah dibuat oleh server sebelumnya. Untuk menda patkankey tersebut penulis telah melakukan konfigurasidi ThingsBoard dengan menambahkan Device Profiles dan daftar Device di ThingsBoard. Setelah itu akan ada kode unik dari device dan scret key yang selanjutnya disalin ke kode program perangkat. Setelah semua proses dilakukan, kode program di upload dan untuk memastikan perangkat sudah berhasil Provisioning ke server dapat dilihat melalui serial monitor dari IDE Visual Studio Code. Proses Provisioning yang dilakukan penulis berhasil, itu ditunjukkan dalam serial monitor yang berisi id perangkat, jenis kredensial, dan isinya.

Pada penelitian ini penulis hanya melakukan Provisioning perangkat ke server pada satu perangkat saja. Artinya jika melakukan Provisioning untuk perangkat lainnya penulis perlu melakukan tahapan-tahapan konfigurasi secara satu persatu. Hal tersebut cukup menyita waktu jika ada banyak perangkat yang harus terhubung ke server ThingsBoard. Sekiranya untuk penelitian selanjutnya adalah bagaimana cara agar banyak perangkat dapat di Provisioning dalam waktu yang bersamaan dengan tujuan menghemat dan efisiensi waktu dengan catatan keamanan dan skalabilita s dari server y ang terjamin. 


\section{DAFTAR RUJUKAN}

[1] A. Mavromatis, A. P. Da Silva, K. Kondepu, D. Gkounis, R. Nejabati, and D. Simeonidou, "A Software Defined Device Provisioning Framework Facilitating Scalability in Internet of Things," IEEE 5G World Forum, 5GWF 2018 - Conf. Proc., no. July, pp. 446-451, 2018, doi: 10.1109/5GWF.2018.8516955.

[2] A. Dawod, D. Georgakopoulos, P. P. Jayaraman, and A. Nirmalathas, "An IoT-owned service for global IoT device discovery, integration and (Re)use," Proc. - 2020 IEEE 13th Int. Conf. Serv. Comput. SCC 2020, pp. 312 320, 2020, doi: 10.1109/SCC49832.2020.00048.

[3] D. Wang, S. Lee, Y. Zhu, and Y. Li, "A zero human-intervention provisioning for industrial IoT devices," Proc. IEEE Int. Conf. Ind. Technol., no. MiM, pp. 1271-1276, 2017, doi: 10.1109/ICIT.2017.7915546.

[4] L. O. Aghenta and M. T. Iqbal, "A Low-Cost, Open Source IoT-Based SCADA System Design , and Implementation for Photovoltaics."

[5] T. L. Scott and A. Eleyan, "CoAP based IoT data transfer from a Raspberry Pi to Cloud," 2019 Int. Symp. Networks, Comput. Commun. ISNCC 2019, pp. 1-6, 2019, doi: 10.1109/ISNCC.2019.8909150.

[6] M. Henschke, X. Wei, and X. Zhang, "Data Visualization for Wireless Sensor Networks Using ThingsBoard," 2020 29th Wirel. Opt. Commun. Conf. WOCC 2020, 2020, doi: 10.1109/WOCC48579.2020.9114929.

[7] L. T. De Paolis, V. De Luca, and R. Paiano, "Sensor data collection and analytics with thingsboard and spark streaming," EESMS 2018 - Environ. Energy, Struct. Monit. Syst. Proc., pp. 1-6, 2018, doi: 10.1109/EESMS.2018.8405822.

[8] M. Alam, K. A. Shakil, and S. Khan, Internet of things (IoT): Concepts and applications. 2020.

[9] L. Verderame et al., "A secure cloud-edges computing architecture for metagenomics analysis," Futur. Gener. Comput. Syst., vol. 111, pp. 919-930, 2020, doi: 10.1016/j.future.2019.09.013.

[10] thingsboard.io, "Device Provisioning." https:/thingsboard.io/docs/user-guide/device-provisioning/.

[11] J. P. Dias, F. Couto, A. C. R. Paiva, and H. S. Ferreira, "A brief overview of existing tools for testing the internetof-things," Proc. - 2018 IEEE 11 th Int. Conf. Softw. Testing, Verif. Valid. Work. ICSTW 2018, pp. 104-109, 2018, doi: 10.1109/ICSTW.2018.00035. 